Received: 04.12 .2017

Revised: 26.01 .2018

Accepted: 23.03 .2018

DOI: $10.17804 / 2410-9908.2018 .3 .033-042$

\title{
APPLICATION OF THE PARETO CRITERION TO SELECTING THE OPTIMAL COMPOSITION OF THE CHARGE MATERIAL FOR THE MANUFACTURE OF A COMPOSITE BLANK
}

\author{
A. G. Zalazinskiy ${ }^{\text {a)}}$, D. I. Kryuchkov ${ }^{\text {b) }}$, V. G. Titov ${ }^{\text {c)* }}$ \\ Institute of Engineering Science, Ural Branch of the Russian Academy of Sciences, \\ 34, Komsomolskaya St., Ekaterinburg, 620049, Russian Federation \\ a) (iD http://orcid.org/0000-0001-8352-5475, ख zalaz@list.ru; ${ }^{\text {b) }}$ (iD http://orcid.org/0000-0001-8585-354, \\ 凶kru4koff@bk.ru; ${ }^{c)}$ iD https://orcid.org/0000-0002-1010-9099, 国 tit@imach.uran.ru \\ *Corresponding author. E-mail: tit@imach.uran.ru \\ Address for correspondence: ul. Komsomolskaya, 34, Ekaterinburg, 620049, Russian Federation \\ Tel.: +7-343-375-35-79
}

The possibility of usingVT-22 alloy powder produced from extrusion waste is considered. It is shown that it is impossible to obtain high-quality pressing by the conventional method of presssintering. The results of experimental investigations of the mechanical properties of briquettespressed and sintered from compositions consisting of powders produced from the VT-22 highstrength titanium alloy with additives of thePTM-1 titanium powder and the PV-N70Yu30 nickelaluminum alloy powder are given. A problem is formulated for selecting the optimal composition of the mixture of the composite material providing required mechanical characteristics and cost of the semi-finished products. The Pareto-optimal composition of the composite material charge has been obtained.

Keywords: Pareto-optimal, composite pressing, noncompact titanium-based raw material, density, compressive strength.

\section{References}

1. Ilyin A.A., Kolachev B.A., Polkin I.S. Titanovye splavy. Sostav, struktura, svoistva. Spravochnik [Titanium Alloys. Composition, Structure, Properties. Reference Book]. Moscow, VILS-MATI Publ., 2009, 520 p. (In Russian).

2. Andreev A.A., Antoshkin N.F., Borzetsovskaya K.M. et al. Plavka i litye titanovykh splavov [Melting and Casting of Titanium Alloys]. Moscow, Metallurgiya Publ., 1978, 383 p. (In Russian).

3. Powder Metallurgy of Titanium Alloys, ed. by Froes F.H. and Smugeresky J.E. Proceedings Publication of the Metallurgical Society of the American Institute of Mining, Metallurgical and Petroleum Engineers, Las Vegas, Nevada, 1980.

4. Ustinov V.S., Olesov U.G., Drozdenko V.A., Antipin L.N. Poroshkovaya metallurgiya titana [Powder Metallurgy of Titanium]. Moscow, Metallurgiya Publ., 1981, 248 p. (In Russian).

5. Kobelev A.G., Lysak V.I., Chernyshev V.N., Kuznetsov E.V. Materialovedenie $i$ tekhnologii kompozitsionnykh materialov [Material Science and Technologies of Composite Materials]. Moscow, Intermet Engineering Publ., 2006, 365 p. (In Russian).

6. Kryuchkov D.I., Zalazinskiy A.G., Berezin I.M., Romanova O.V. Modelling of compaction of titanium composite powders. Diagnostics, Resource and Mechanics of materials and structures, 2015, iss. 1, pp. 48-60. DOI: 10.17804/2410-9908.2015.1.048-060. Available at: http://dreamjournal.org/DREAM_Issue_1_2015_Kryuchkov_D._I._et_al..pdf

For citation: Zalazinsky A.G., Kryuchkov D.I., Titov V.G. Application of the Pareto criterion to selecting the optimal composition of the charge material for the manufacture of a composite blank // Diagnostics, Resource and Mechanics of materials and structures. - 2018. - Iss. 3. - P. 33-42. - DOI: 10.17804/2410-9908.2018.3.033042 . 
7. Moiseev V.N., Sysoeva N.V., Ermolova M.I. Heat treatment of granulated VT22 alloy. Metal Science and Heat Treatment, 1996, vol. 38, nos. 1-2, pp. 42-45. DOI: 10.1007/BF01153872. 8. Podinovsky V.V., Nogin V.D. Pareto-optimalnye resheniya mnogokriterialnykh zadach [Pareto-Optimal Solutions for Multicriteria Problems]. Moscow, Nauka Publ., 1982, 256 p. (In Russian).

9. Ivasishin O.M., Savvakin D.G., Bondareva K.A. et al. Production of titanic alloys and parts by economical method of powder metallurgy for large-scale industrial use. Nauka i innovatsii, 2005, vol. 1, no. 2, pp. 44-57.

10. Kryuchkov D.I., Zalazinsky A.G., Polyakov A.P., Berezin I.M., Shchennikova T.L., Zalazinsky G.G. Selecting an optimum composition of a titanium-based powder composite material for blank pressing. Kuznechno-Shtampovochnoe Proizvodstvo. Obrabotka Materialov Davleniem, 2014, no. 6, pp. 34-38. (In Russian). 
Подана в журнал: 04.12.2017

УДК 621.762-419.8

DOI: $10.17804 / 2410-9908.2018 .3 .033-042$

\title{
ВЫБОР ОПТИМАЛЬНОГО СОСТАВА ШИХТЫ ДЛЯ ИЗГОТОВЛЕНИЯ КОМПОЗИТНОЙ ЗАГОТОВКИ С ИСПОЛЬЗОВАНИЕМ КРИТЕРИЯ ПАРЕТО
}

\author{
А. Г. Залазинский ${ }^{\mathrm{a}}$, Д. И. Крючков ${ }^{\text {()) }}$ В. Г. Титов ${ }^{\text {в)* }}$ \\ Институт машиноведения УрО РАН, ул. Комсомольская, 34, г. Екатеринбург, Российская Федерация

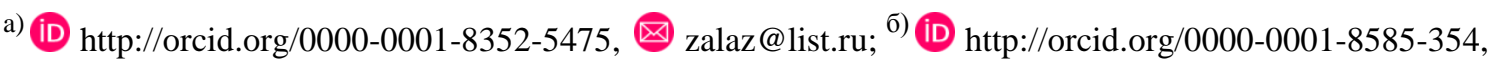 \\ ه kru4koff@bk.ru; ${ }^{\text {B) }}$ iD https://orcid.org/0000-0002-1010-9099, $ه$ tit@imach.uran.ru; \\ *Ответственный автор. Электронная почта: tit@imach.uran.ru \\ Тел.: +7-343-375-35-79
}

Рассмотрена возможность использования порошка сплава ВТ-22, полученного из отходов прессования. Показано, что невозможно из порошка получить качественную прессовку обычным методом прессования-спекания. Приведены результаты экспериментального исследования механических свойств спрессованных и спеченных брикетов состоящих из порошков, полученных из высокопрочного сплава титана ВТ-22 с добавками порошка титана ПТМ-1 и порошка сплава никель-алюминий ПВ-Н70Ю30. Осуществлена постановка задачи для выбора оптимального состава шихты композитного материала, обеспечивающего требуемые механические характеристики и стоимость полуфабрикатов. Получен оптимальный по Парето состав шихты композиционного материала.

Ключевые слова: оптимальный по Парето, прессование композита, некомпактное титансодержащее сырье, плотность, прочность на сжатие.

\section{1. Введение}

Материалы из титана используются в достаточно многих областях производства [1]. Производство таких материалов отличается высокой энергоемкостью и значительным количеством трудно перерабатываемых [2]. Известным методом переработки отходов металлургического производства является порошковая металлургия, позволяющая существенно уменьшить материалоемкость продукции и объем механической обработки $[3,4]$. Также порошковая металлургия дает возможность для создания новых композиционных материалов [5].

Титановые порошки получают двумя способами: распылением струи жидкого металла нейтральным газом и распылением под действием центробежной силы. Последний метод заключается в расплавлении вращающегося электрода из титана, от которого под действием центробежной силы отрываются капли жидкого металла, кристаллизующегося на лету в гранулы [9].

Цель работы - исследование физико-технологических свойств порошка ВТ-22 и порошков на основе этого, выбор оптимального по Парето состава шихты для изготовления композитной заготовки.

\section{2. Методы исследования порошка сплава ВТ-22}

Объект исследования - порошок сплава ВТ-22, полученный распылением плазмой методом вращающегося электрода.

Гранулометрический состав порошков определяли по размерам и форме на анализаторе частиц CAMSIZER-XT (Retsch Technology, Германия), который позволяет проводить

For citation: Zalazinsky A.G., Kryuchkov D.I., Titov V.G. Application of the Pareto criterion to selecting the optimal composition of the charge material for the manufacture of a composite blank // Diagnostics, Resource and Mechanics of materials and structures. - 2018. - Iss. 3. - P. 33-42. - DOI: 10.17804/2410-9908.2018.3.033042 . 
измерение размера частиц материалов в диапазоне от 3 мкм до 3 мм в режиме on-line, при использовании динамического анализа цифрового изображения, поступающего с двух камер с частотой съемки 275 кадр./с. Минимальная величина навески 5 г. В результате обработки данных получены кривая плотности распределения частиц по размерам, средний размер частиц, коэффициенты формы частиц: сферичность, симметричность, соотношение ширины к длине; количественные показатели частиц с данной формой.

Определение насыпной плотности металлических порошков выполнено по ГОСТ 19440-74. Текучесть количественно оценивали по времени истечения определенной массы порошка (50 г) в секундах через воронку с калиброванным выходным отверстием (2,5 мм) и углом раствора $60^{\circ}$ (ГОСТ 20899-75).

Метод для измерения плотности утряски (ГОСТ 25279-80) основан на уплотнении порошка встряхиванием навески определенной массы в мерном цилиндре до установившегося значения объема, занимаемого порошком, с последующим вычитанием его плотности. Морфологию частиц исследовали на сканирующем электронном микроскопе CarlZeiss EVO 40, предназначенном для получения изображений объектов в «прямых» электронах и электронах обратного рассеяния.

Исследование микроструктуры частиц проводили на металлографических шлифах на оптическом микроскопе Olympus GX-51 (Япония) в центре коллективного пользования «Рациональное природопользование и передовые технологии материалов» «Урал-М».

Фазовый состав определяли в ИМЕТ УрО РАН на дифрактометре D8ADVANCE(Druker AXS, Германия), который позволяет исследовать вещества и материалы в твердом, аморфном и жидком состоянии в температурном интервале от -190 до $2000{ }^{\circ} \mathrm{C}$ на воздухе, в вакууме и инертной атмосфере, обеспечивает высокую точность, экспрессную съемку и быструю обработку экспериментальных данных.

\section{3. Результаты исследований порошка сплава ВТ-22}

Сплав ВТ-22 создан на основе системы Ti-Al-Mo-V с добавками Fe и $\mathrm{Cr}$ (табл. 1). Плотность распределения частиц по размерам после распыления представлена на рис. 1.

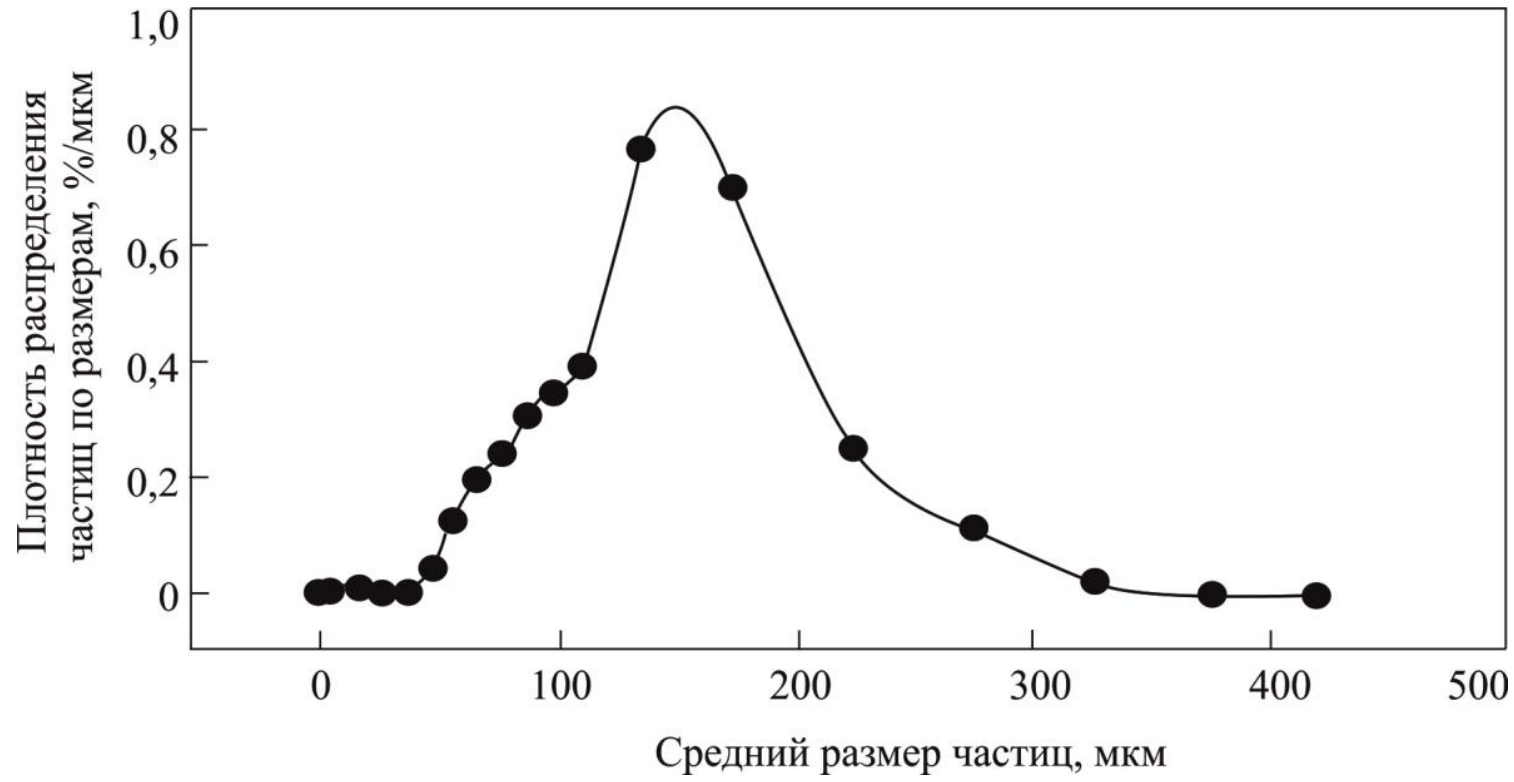

Рис. 1. Плотность распределения частиц по размерам порошка сплава ВТ-22

Порошок, полученный распылением плазмой, представлен фракцией менее 440 мкм, имеет средний размер частиц 156 мкм, выход фракции менее 200 мкм - 80 мас. \%. Частицы порошка имеют округлую и сферическую форму: средний коэффициент сферичности - 0,722,

For citation: Zalazinsky A.G., Kryuchkov D.I., Titov V.G. Application of the Pareto criterion to selecting the optimal composition of the charge material for the manufacture of a composite blank // Diagnostics, Resource and Mechanics of materials and structures. - 2018. - Iss. 3. - P. 33-42. - DOI: 10.17804/2410-9908.2018.3.033042. 
коэффициент симметричности - 0,876. Морфология и топография поверхности порошка представлена на рис. 2. Поверхность частиц гладкая, оболочка плотная (рис. 2 a).

Таблица 1 - Химический состав сплава ВТ-22 и порошка, полученного распылением сплава плазмой, мас. \%

\begin{tabular}{|l|c|c|c|c|c|c|c|c|c|c|}
\hline \multirow{2}{*}{$\begin{array}{c}\text { Объект } \\
\begin{array}{c}\text { исследо- } \\
\text { вания }\end{array}\end{array}$} & $\mathrm{Ti}$ & $\mathrm{Fe}$ & $\mathrm{Cr}$ & $\mathrm{Al}$ & $\mathrm{V}$ & $\mathrm{Mo}$ & $\mathrm{C}$ & $\mathrm{O}$ & $\mathrm{N}$ & $\mathrm{H}$ \\
\cline { 2 - 11 } \\
\hline $\begin{array}{l}\text { Сплав } \\
\text { ВТ-22 }\end{array}$ & Основа & $0,5-1,5$ & $0,5-2$ & $4,4-5,9$ & $4-5,5$ & $4-5,5$ & $\leq 0,1$ & $\leq 0,2$ & $\leq 0,05$ & $\leq 0,015$ \\
\hline Порошок & Основа & 0,85 & 0,93 & 5,75 & 4,88 & 4,56 & 0,018 & 0,157 & & 0,0018 \\
\hline
\end{tabular}

По ГОСТ 19807-91.

Исследование металлографических шлифов порошка показало наличие мелких внутренних пор в частицах (рис. 2 б). На рис. 2 в показана микроструктура порошка, характерная для литого состояния. Неоднородное по размеру зерно состоит из $\beta$-фазы с пластинчатым внутренним строением. На отдельных частицах есть редкие выделения: светлые карбиды, темные сферы со светлой точкой внутри - фаялиты или $\mathrm{SiO}_{2}$.

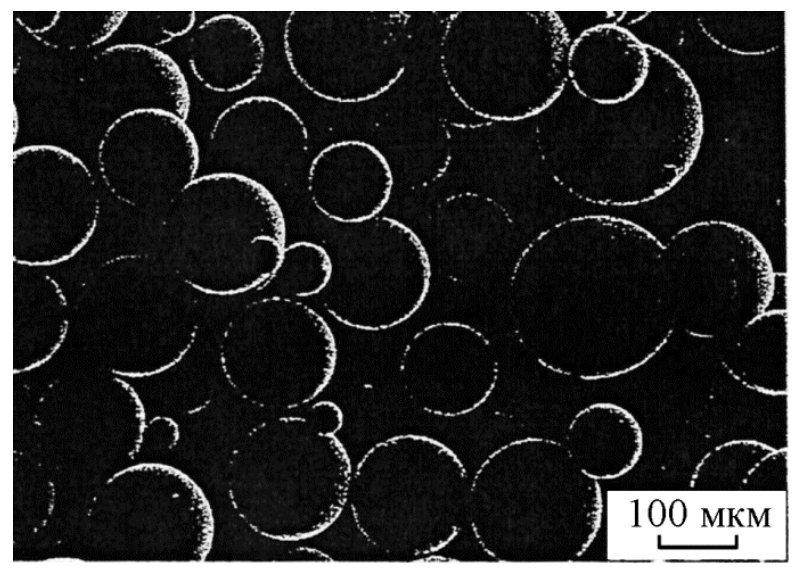

$a$

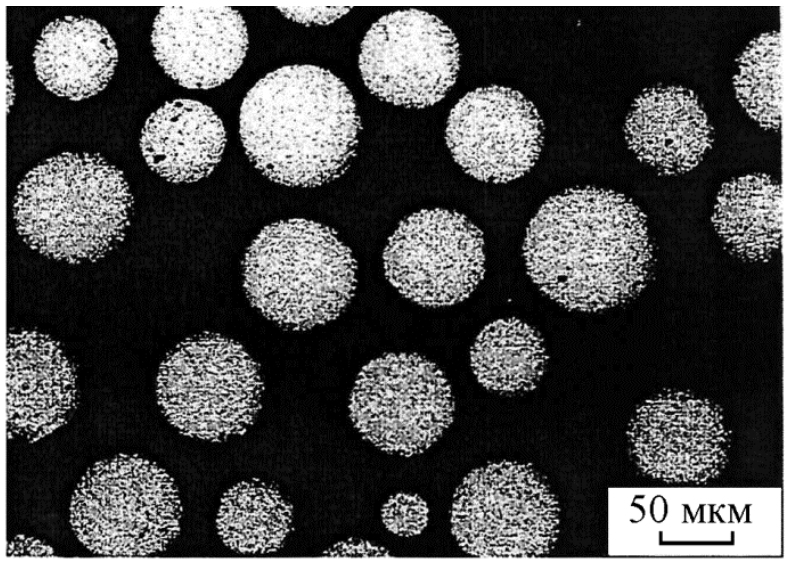

6

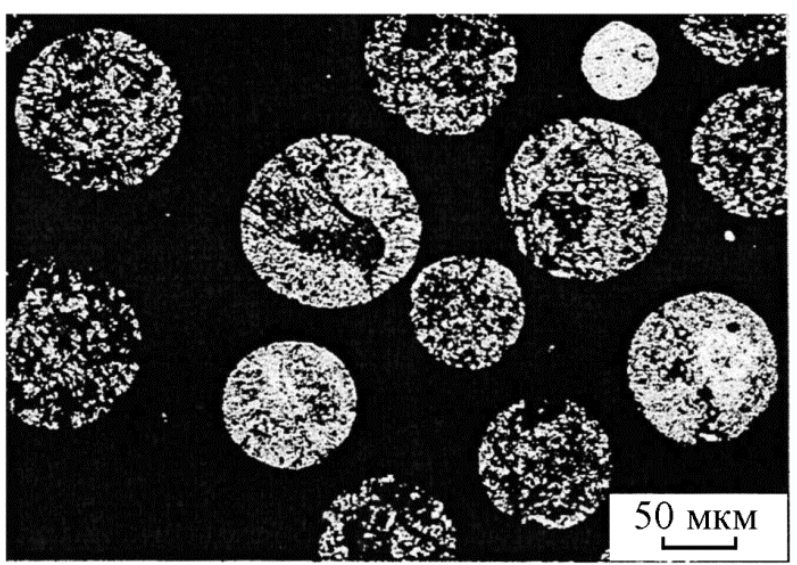

B

Рис. 2. Микроструктура порошка, полученного из сплава ВТ-22 распылением плазмой

For citation: Zalazinsky A.G., Kryuchkov D.I., Titov V.G. Application of the Pareto criterion to selecting the optimal composition of the charge material for the manufacture of a composite blank // Diagnostics, Resource and Mechanics of materials and structures. - 2018. - Iss. 3. - P. 33-42. - DOI: 10.17804/2410-9908.2018.3.033042. 
Экспериментально определены насыпная плотность порошка $\left(\mathrm{C}_{H}\right)$, плотность после утряски $\left(\mathrm{C}_{y}\right)$, степень утряски ( $\left.\xi\right)$ и текучесть $(\mathrm{T})$.

По программе, разработанной в ИМЕТ УрО РАН, рассчитаны насыпная плотность и плотность после утряски. Результаты приведены в табл. 2. Экспериментальные и расчетные данные хорошо согласуются - расхождение составляет 1-3,2\%.

Программа также позволяет рассчитать удельную поверхность порошка. По ней можно рассчитать насыпную плотность, плотность после утряски и удельную поверхность для смеси разных порошков заданного состава по известной плотности и среднему размеру частиц.

Таблица 2 - Физико-технологические свойства порошка сплава ВТ-22

\begin{tabular}{|l|c|c|c|c|}
\hline \multicolumn{1}{|c|}{ Результат } & $\begin{array}{c}\text { Насыпная } \\
\text { плотность порошка, } \\
\mathrm{C}_{н}, \Gamma / \mathrm{cm}^{3}\end{array}$ & $\begin{array}{c}\text { Плотность } \\
\text { после утряски, } \\
\mathrm{C}_{y}, \Gamma / \mathrm{cm}^{3}\end{array}$ & $\begin{array}{c}\text { Степень } \\
\text { утряски, } \\
\xi, \%\end{array}$ & $\begin{array}{c}\text { Текучесть, } \\
\text { Т, с (50 г) }\end{array}$ \\
\hline Эксперимент & 2,53 & 2,91 & 15,02 & 26,1 \\
\hline Расчет & 2,45 & 2,88 & 17,55 & - \\
\hline
\end{tabular}

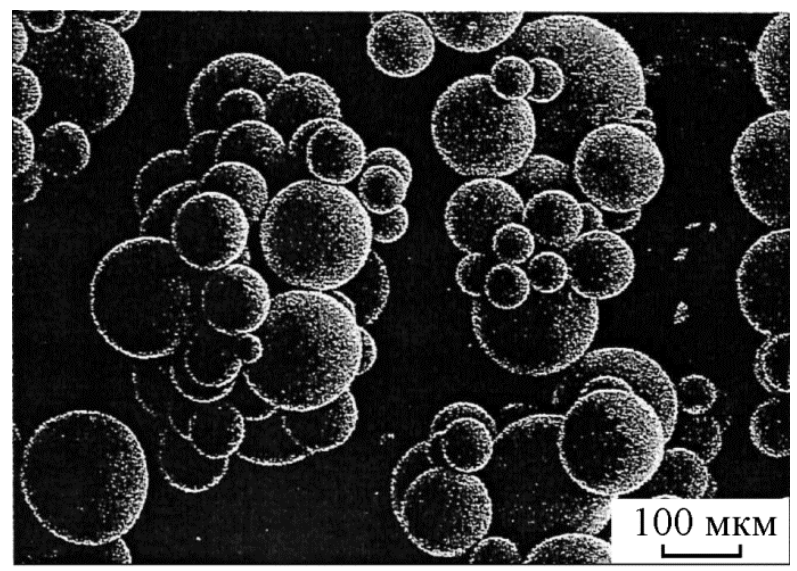

$a$

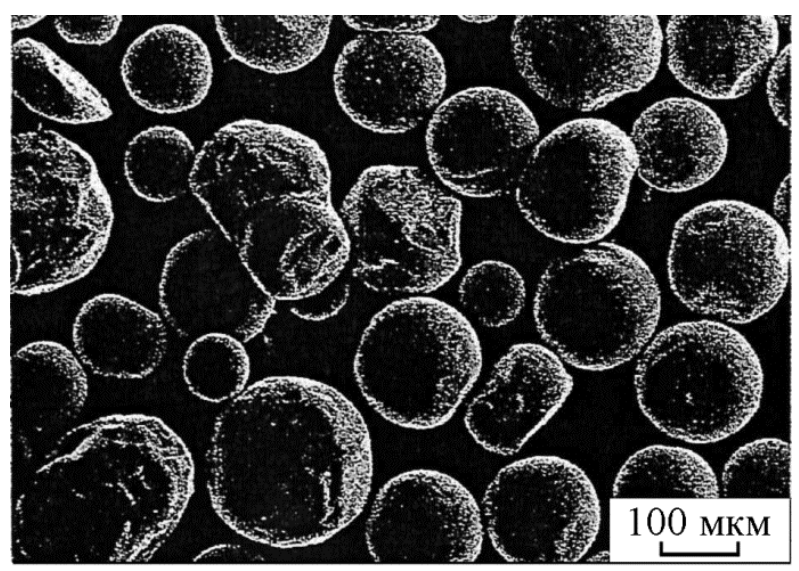

B

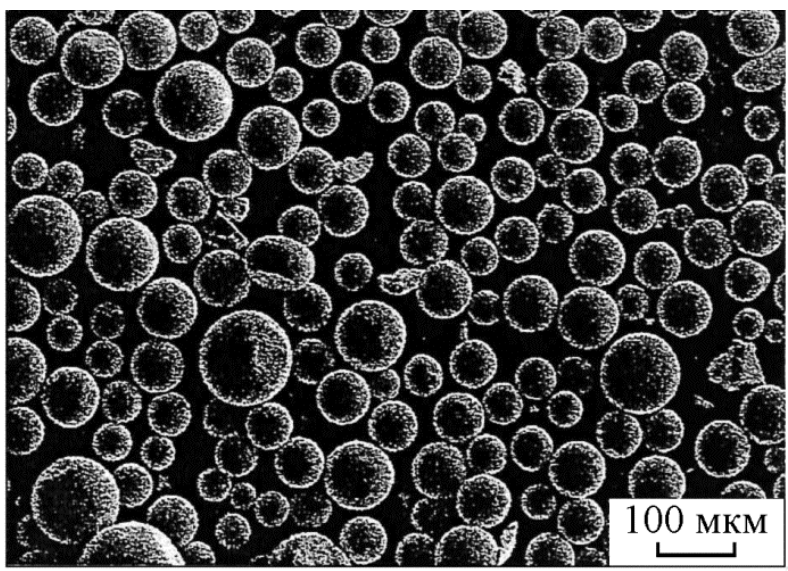

$\sigma$

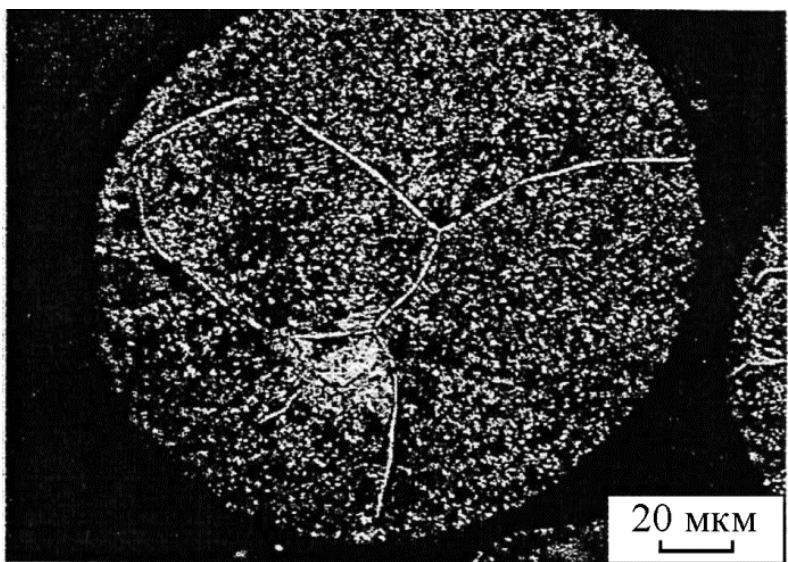

2

Рис. 3. Морфология порошка: $a$ - после отжига; $\sigma$ - после измельчения отожженного порошка; фракция менее 50 мкм, в - фракция более 50 мкм; 2 - после отжига

For citation: Zalazinsky A.G., Kryuchkov D.I., Titov V.G. Application of the Pareto criterion to selecting the optimal composition of the charge material for the manufacture of a composite blank // Diagnostics, Resource and Mechanics of materials and structures. - 2018. - Iss. 3. - P. 33-42. - DOI: 10.17804/2410-9908.2018.3.033042. 
Отжиг порошка проводили в вакууме ступенчато: при $750{ }^{\circ} \mathrm{C}$ в течение 1 ч, охлаждение с печью до $200{ }^{\circ} \mathrm{C}$, затем нагрев до $650{ }^{\circ} \mathrm{C}, 3$ ч, охлаждение с печью. Частицы спеклись, но спек легко разрушается при истирании в ступке. Гранулометрический состав порошка после отжига изменился незначительно. Фракцию более 200 мкм, полученную после спекания измельчили в виброистирателе ИВ-микро в течении 1 ч. На рис. 3 показана морфология частиц крупнее 200 мкм (рис. 3 a), фракции менее 50 мкм (рис. 3 б) и более 50 мкм (рис. 3 в), полученные после измельчения. Исходная фракция (рис. 3 a) представлена спеками частиц, после измельчения спеки разрушены - частицы фракции менее 50 мкм представлены в основном сферическими частицами, встречаются осколки более крупных частиц (рис. 3 б), порошок фракции более 50 мкм имеет частицы неправильной формы, образовавшиеся в результате измельчения (рис. 3 в). Частицы состоят из $(\alpha+\beta)$-фаз с близким количеством $\alpha$ - и $\beta$-фаз (рис. 3 г).

Прессовки из порошка сплава ВТ-22 как из исходного, так и из порошка после отжига рассыпаются, частицы деформируются, но не сцепляются между собой. Поверхность частиц гладкая, плотная, основа частиц представлена структурой пластинчатого типа. Порошок в исходном состоянии может быть переработан только горячим прессованием, поэтому дальнейшие исследования по получению порошковых материалов на его основе проведено с добавлением порошков с развитой поверхностью [10] в исходный порошок.

\section{4. Методы исследования порошкового композита}

Объект исследования - порошковый композит, состоящий из порошка, полученного из сплава ВТ-22 распылением плазмой, с добавками порошка титана ПТМ-1, полученного гидридно-кальциевым способом, порошка сплава никель-алюминий ПВ-Н70Ю30.

С целью выбора оптимального состава порошкового композита для производства изделий, работающих в условиях циклических силовых и температурных нагрузок, стойких к воздействию агрессивных сред, провели несколько серий отсеивающих экспериментов, результаты которых описаны в [6]. В работе исследовали процесс уплотнения смеси порошка, полученного из сплава ВТ-22 распылением плазмой, с добавками порошка титана ПТМ-1, полученного гидридно-кальциевым способом, порошка сплава никель-алюминий ПВН70Ю30. Порошок сплава ВТ-22 выбран для повышения прочностных свойств композиционного материала. Исследуемый порошок представлен фракцией менее 440 мкм, средний размер частиц - 156 мкм.

Образцы прессовали при давлениях 1000 МПа. Прессование брикетов проводили на гидравлическом прессе $\mathrm{MC}-500$ в закрытой разборной пресс-форме. После прессования получены брикеты плотностью $\rho_{\text {отн }}=0,71 \ldots 0,85$ от теоретической. Качество брикетов удовлетворительное. В ряде случаев для неспеченных образцов с содержанием ВТ-22 60 \% и выше наблюдалось осыпание нижней кромки. Спрессованные образцы спекались в вакууме $10^{-3}$ МПа в течение 2 ч при температуре $1200{ }^{\circ} \mathrm{C}$, далее нагревались до температуры спекания 1 ч. Режим спекания выбран в соответствии с рекомендациями [7]. Использовалась вакуумная электропечь сопротивления камерного типа СНВЭ-9/18.

Прочность брикетов оценивали по результатам опытов на осевое сжатие на универсальной испытательной машине ZWICK BT1-FR050THW/A1K. В момент начала разрушения заготовки фиксировали усилие и определяли предел прочности на сжатие $\sigma_{p}$ при текущей плотности.

For citation: Zalazinsky A.G., Kryuchkov D.I., Titov V.G. Application of the Pareto criterion to selecting the optimal composition of the charge material for the manufacture of a composite blank // Diagnostics, Resource and Mechanics of materials and structures. - 2018. - Iss. 3. - P. 33-42. - DOI: 10.17804/2410-9908.2018.3.033042. 
Таблица 3 - Результаты прессования композитного материала из титансодержащего материала

\begin{tabular}{|c|c|c|c|c|c|c|}
\hline \multirow{2}{*}{ № } & \multicolumn{3}{|c|}{ Варьируемые факторы } & \multicolumn{3}{c|}{ Критерии оптимизации } \\
\cline { 2 - 7 } & $\mathrm{X} 1$ & $\mathrm{X} 2$ & $\mathrm{X} 3$ & Y1, МПа & Y2 & Ү3, у.е./кг \\
\hline 1 & 50 & 50 & 0 & 1356 & 0,806 & 3000 \\
\hline 2 & 60 & 30 & 10 & 1103 & 0,812 & 2300 \\
\hline 3 & 60 & 20 & 20 & 834 & 0,783 & 2100 \\
\hline 4 & 60 & 10 & 30 & 535 & 0,776 & 1900 \\
\hline 5 & 65 & 25 & 10 & 1056 & 0,789 & 2050 \\
\hline 6 & 65 & 15 & 20 & 768 & 0,756 & 1850 \\
\hline 7 & 65 & 5 & 30 & 410 & 0,754 & 1650 \\
\hline 8 & 70 & 30 & 0 & 594 & 0,771 & 2000 \\
\hline 9 & 70 & 25 & 5 & 967 & 0,785 & 1900 \\
\hline
\end{tabular}

Результаты экспериментального исследования показаны в табл. 3. Здесь X1; X2; X3 варьируемые факторы, представляющие процентное содержание по массе компонент шихты: ВТ-22 (X1); ПТМ-1 (X2); ПВ-Н70Ю30 (X3). Параметры, выбранные в качестве критериев оптимизации, обозначены так: Y1 (предел прочности), Y2 (относительная плотность), Y3 (стоимость).

\section{5. Результаты исследования порошкового композита}

Задача оптимизации композиционного материала заключается в следующем: определить оптимальный состав шихты, при котором прессованием некомпактного титансодержащего сырья получается заготовка с максимальными механическими свойствами, при минимальных затратах на их получение.

По значениям критериев оптимизации Y1, Y2, Y3 (табл. 3) выбраны 6 оптимальных вариантов $(1,2,5,6,7,9)$, по Парето [8]. Алгоритм выбора представлен на рис. 4. Построение множества оптимальных по Парето решений является одним из первых этапов большого числа методов многокритериальной оптимизации. Один из методов решения - окончательный выбор оптимального варианта производится эвристически (на основании опыта, интуиции, неформализуемых соображений) лицом, принимающим решение. Другой подход - составить по возможности наиболее полный перечень критериев и потом исключить из рассмотрения несущественные критерии.

В данном случае значения критериев оптимизации Y1, Y2, Y3 6 оптимальных вариантов (по Парето) были нормированы таким образом, чтобы привести их к одной шкале измерения:

$$
\begin{aligned}
& \mathrm{Y} 1 \mathrm{~N}=(\mathrm{Y} 1-\min (\mathrm{Y} 1)) /(\max (\mathrm{Y} 1)-\min (\mathrm{Y} 1)) \\
& \mathrm{Y} 2 \mathrm{~N}=(\mathrm{Y} 2-\min (\mathrm{Y} 2)) /(\max (\mathrm{Y} 2)-\min (\mathrm{Y} 2)) \\
& \mathrm{Y} 3 \mathrm{~N}=(\mathrm{Y} 3-\min (\mathrm{Y} 3)) /(\max (\mathrm{Y} 3)-\min (\mathrm{Y} 3))
\end{aligned}
$$

Так как значения критериев оптимизации Y1, Y2 нужно максимизировать, а Y3 - минимизировать, то значения Y3N были обращены таким образом, чтобы значения критерия оптимизации нужно было максимизировать:

$$
\mathrm{Y} 3 \mathrm{NO}=1-\mathrm{Y} 3 \mathrm{~N} .
$$

For citation: Zalazinsky A.G., Kryuchkov D.I., Titov V.G. Application of the Pareto criterion to selecting the optimal composition of the charge material for the manufacture of a composite blank // Diagnostics, Resource and Mechanics of materials and structures. - 2018. - Iss. 3. - P. 33-42. - DOI: 10.17804/2410-9908.2018.3.033042 . 
В системе координат Y1N, Y2N, Y3NO определили длины векторов 6 оптимальных по Парето вариантов от начала координат. Эти длины следующие: 1,$3431 ; 1,3437 ; 1,1514$; 0,$9328 ; 1 ; 1,1385$. Начало этой системы координат является худшей по оптимальности точкой. Тогда выберем точку максимально удаленную от худшей по оптимальности точки, т.е. максимальную длину вектора. Максимальную длину вектора имеет 2 вариант. На основании этого 2 вариант был выбраноптимальным. Получены следующие оптимальные по Парето значения: $\mathrm{X} 1=60 ; \mathrm{X} 2=30 ; \mathrm{X} 3=10$.

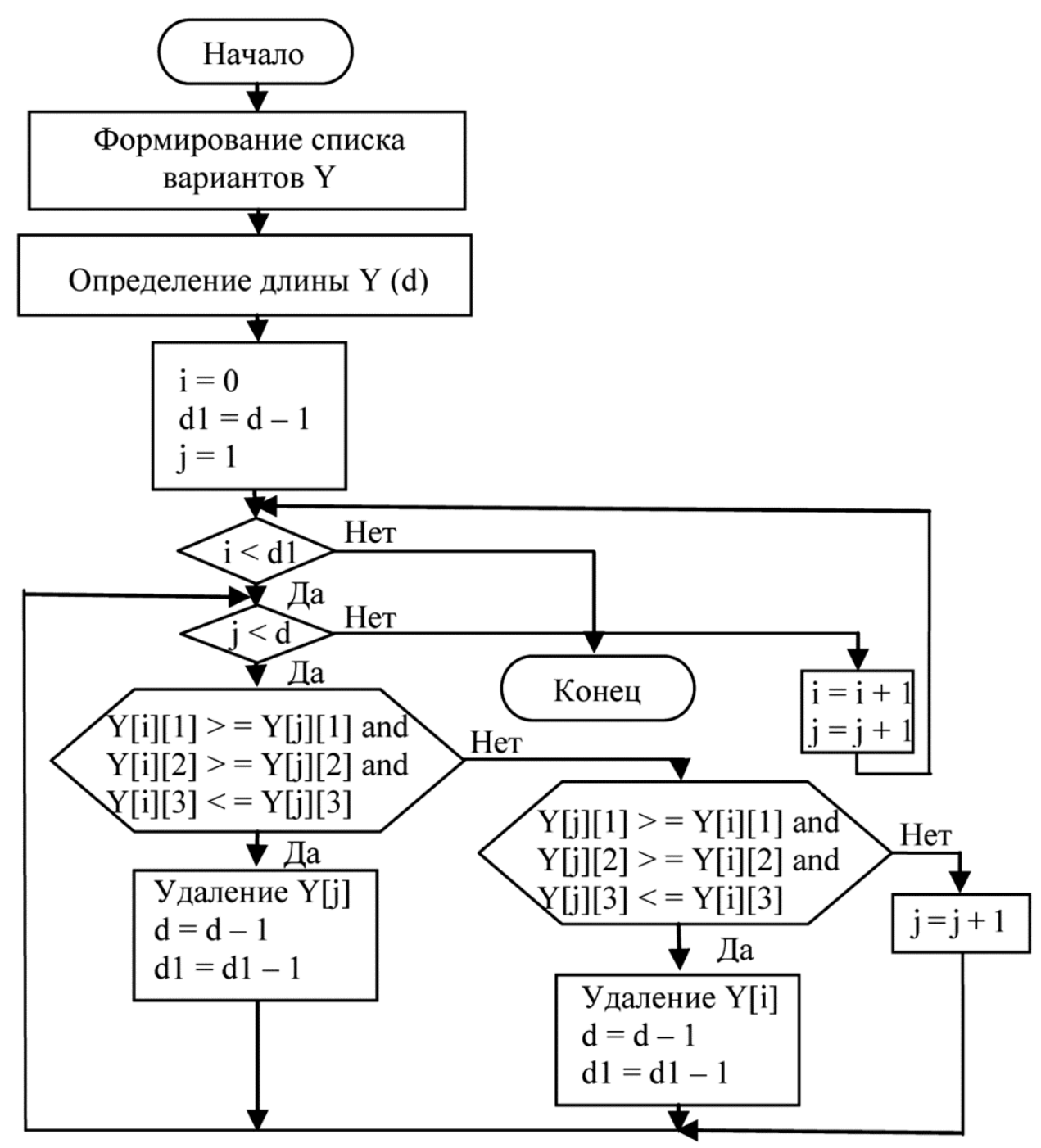

Рис. 4. Алгоритм выбора оптимальных (по Парето) вариантов

\section{6. Заключение}

Порошок сплава ВТ-22, полученный распылением плазмой методом вращающегося электрода, обладает следующими физико-технологическими свойствами при размере частиц менее 440 мкм - средний размер 156 мкм при выходе фракции менее 200 мкм - 80 мас. \%: насыпная плот-

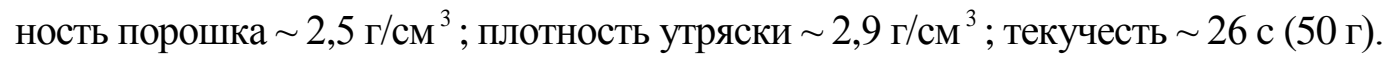

На основе анализа данных экспериментов даны рекомендации по выбору оптимального состава композиционного материала. Для этого разработана программа и использована методика оптимизации получения композита из некомпактного титансодержащего сырья, включающая в себя поиск оптимального состава шихты по Парето. По этой методике был определен следующий оптимальный состав шихты по Парето, 60 \%

For citation: Zalazinsky A.G., Kryuchkov D.I., Titov V.G. Application of the Pareto criterion to selecting the optimal composition of the charge material for the manufacture of a composite blank // Diagnostics, Resource and Mechanics of materials and structures. - 2018. - Iss. 3. - P. 33-42. - DOI: 10.17804/2410-9908.2018.3.033042. 
порошка из сплава ВТ-22; 30 \% порошка титана ПТМ-1; 10 \% порошка сплава никельалюминий ПВ-Н70Ю30.

\section{Литература}

1. Ильин А. А., Колачёв Б. А., Полькин И. С. Титановые сплавы. Состав, структура, свойства : справочник. - М. : ВИЛС-МАТИ, 2009. - 520 с.

2. Плавка и литье титановых сплавов / А. А. Андреев, 3. Ц. Аношкин, К. М. Борзецовская и др. - М. : Металлургия, 1978. - 383 с.

3. Фроус Ф. Х., Смугерески Дж. Е. Порошковая металлургия титановых сплавов : сб. науч. трудов / пер. с англ. - М. : Металлургия, 1985. - 263 с.

4. Порошковая металлургия титана / В. С. Устинов, Ю. Г. Олесов, В. А. Дрозденко, Л. Н. Антипин. - 2-е изд. - М. : Металлургия, 1981. - 248 с.

5. Материаловедение и технология композиционных материалов / А. Г. Кобелев, В. И. Лысак, В. Н. Чернышев, Е. В. Кузнецов. - М. : Интермет Инжиниринг, 2006. - 365 с.

6. Modelling of compaction of titanium composite powders / D. I. Kryuchkov, A. G. Zalazinskiy, I. M. Berezin, O. V. Romanova // Diagnostics, Resource and Mechanics of materials and structures. 2015. - Iss. 1. - P. 48-60. - DOI: 10.17804/2410-9908.2015.1.048-060. - URL: http://dreamjournal.org/DREAM_Issue_1_2015_Kryuchkov_D._I._et_al..pdf

7. Moiseev V. N., Sysoeva N. V., Ermolova M. I. Heat treatment of granulated VT22 alloy // Metal Science and Heat Treatment. - 1996. - Vol. 38, nos. 1-2. - P. 42-45. - DOI: 10.1007/BF01153872.

8. Подиновский В. В., Ногин В. Д. Парето-оптимальные решения многокритериальных задач. - М. : Наука, 1982. - 256 с.

9. Производство титановых сплавов и деталей экономичным методом порошковой металлургии для широкомасштабного промышленного применения / О. М. Ивасишин, Д. Г. Саввакин, К. А. Бондарева и др. // Наука и инновации. - 2005. - Т. 1, № 2. - С. 44-57.

10. Выбор оптимального состава порошкового композиционного материала на основе титана для прессования заготовок / Д. И. Крючков, А. Г. Залазинский, А. П. Поляков, И. М. Березин, Т. Л. Щенникова, Г. Г. Залазинский // Кузнечно-штамповочное производство. Обработка материалов давлением. - 2014. - № 6. - Р. 34-38.

For citation: Zalazinsky A.G., Kryuchkov D.I., Titov V.G. Application of the Pareto criterion to selecting the optimal composition of the charge material for the manufacture of a composite blank // Diagnostics, Resource and Mechanics of materials and structures. - 2018. - Iss. 3. - P. 33-42. - DOI: 10.17804/2410-9908.2018.3.033042 . 